DOT/FAA/AM-99/12

Office of Aviation Medicine Washington, D.C. 20591

\section{Cognitive Style and Learning: Performance of Adaptors and Innovators in a Novel Dynamic Task}

Julia Pounds

Larry L. Bailey

Civil Aeromedical Institute

Federal Aviation Administration

Oklahoma City, Oklahoma 73125

April 1999

Final Report

This document is available to the public through the National Technical Information Service, Springfield, Virginia 22161.

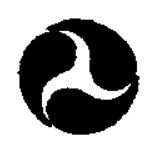

U.S. Department of Transportation

Federal Aviation Administration 


\section{NOTICE}

This document is disseminated under the sponsorship of the U.S. Department of Transportation in the interest of information exchange. The United States Government assumes no liability for the contents thereof. 


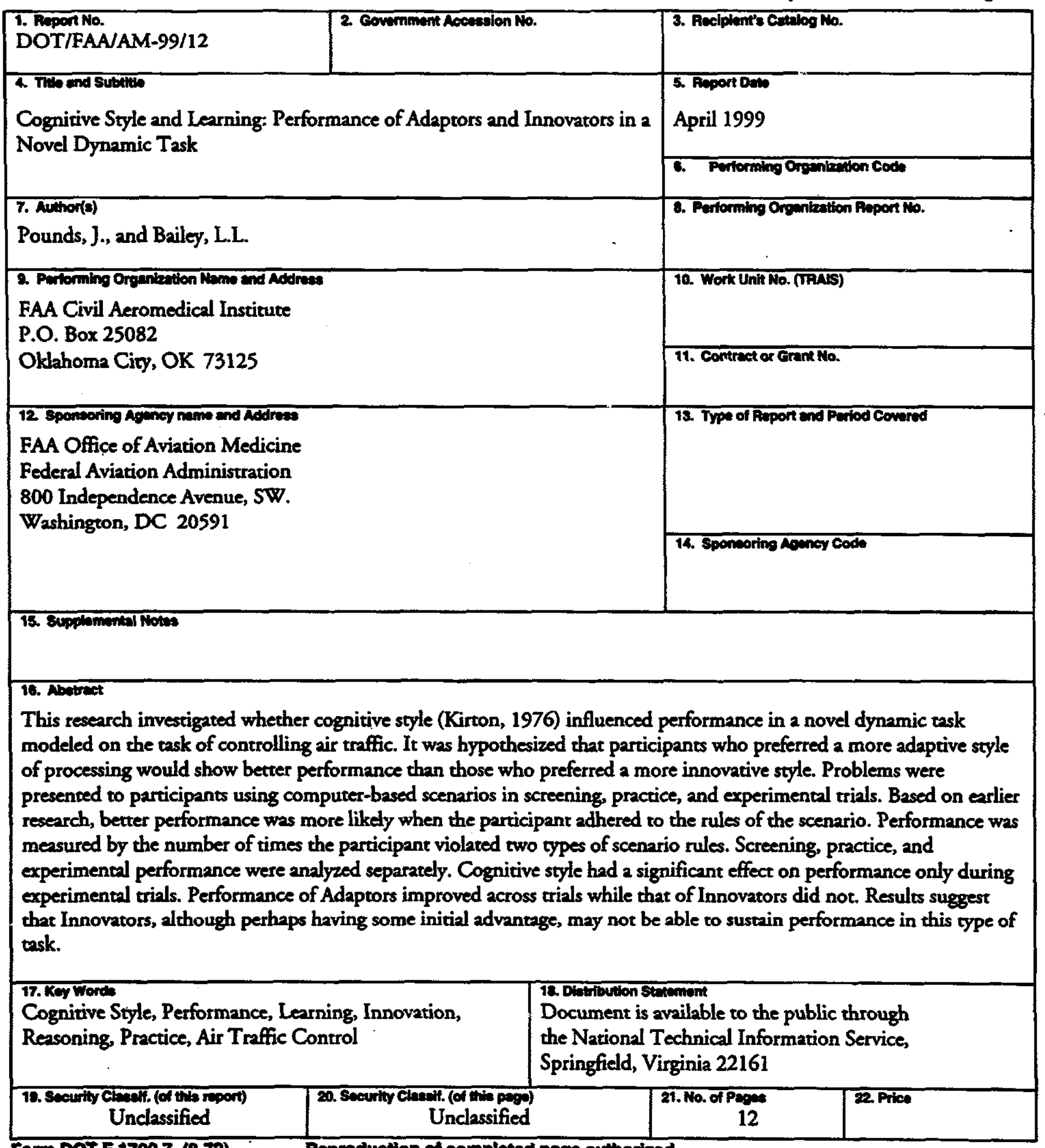

Form DOT F 1700.7 (8-72) Reproduction of completed page authorized




\section{Cognitive Style and Learning: Performance of adaptors and Imnovators in a Novel Dynamic Task}

The Federal Aviation Administration (FAA) is charged with maintaining the U.S. airspace-a vast and increasingly complex transportation system. Highly trained air traffic control specialists (ATCSs) form the crux of the web of radar, computers, and communication facilities that ensure the safety and efficiency of the system (Broach \& Brecht-Clark, 1994). As part of ongoing development, new automation will continue to be implemented into the next century to assist ATCSs, and human interaction with technology is a vital component of this system. Hollnagel, Cacciabue, and Hoc (1995) described the combination of humans and technology to accomplish particular functions as joint systems.

Although both humans and technology are necessary elements of joint systems, the person in charge of controlling the system has responsibility for the system's performance (Hollnagel et al., 1995). This is of little interest in well-bounded situations where arjual vimations match expected conditions. In these situations, rule-based technology handles the human operator's routine tasks extremely well. However, Hollnagel et al. note that the true flexibility of joint systems emerges from the performance of the human operator, who shapes the response of the joint system to real-time unexpected events.

Despite the criticality of human performance in joint systens, liste sesearch tras beess conducted to identify desirable individual characteristics beyond knowledge of the system itself (cf. Chidester, Kanki, Foushee, Dickinson, \& Bowles, 1990; Hoc, Cacciabue, \& Hollnagel, 1995; Zsambok \& Klein, 1997). One area receiving some attention in the technological environment of air traffic control is the relationship between personality variables and successful human performance.

\section{Personality}

Collins, Schroeder, and Nye (1989) assessed the role of anxiety in the prediction of successful performance using the State-Trait. Personality Inventory (STPI; Spidberger, 1979). The STPI is a self-report instrument measuring the personality dimensions of Anxiety, Curiosity, and Anger; scores on the STPI Anxiety subscale predicted individual training outcomes. Specifically, for students tested upon entering the en route air traffic control option at the FAA Academy, higher Anxiety scores were related to increased likelihood of Academy failures/withdrawals, option switches, and field attrition. Also using the STPI, Nye and Collins (1991) found that, for students entering the Academy's nonradar screen program, higher pass rates were associated with those students with higher levels of Curiosity and lower levels of Anxiety and Anger.

Schrceder, Broach, and Young (1993) reviewed several past studies that examined relationships between personality variables, ATCS training, and onthe-job performance. The authors proposed that the conflicting results demonstrated the need for research based on a unifying, psychometrically sound model of personality. Therefore, they employed the Five Factor Model of Personality (NEO-PI; McCrae \& Costa, 1990) to examine the personality characteristics related to the choice of ATCS as an occupation and successful prediction of performance. The NEO-PI Inventory is comprised of five primary subscales: Neuroticism (e.g., calm vs. worrying), Extraversion (e.g., reserved vs. affectionate), Openness to experience (e.8., uncurious vs. curious), Agreenbleness (e.g., suspicious vs. trusting), and Conscientiousness (e.g., lazy vs. hardworking). Based on their analyses, Schroeder and his associates concluded that air traffic students enrolled in the Academy's ATCS Nonradar Screen program had lower than average seores in Neuroticism and higher than average scores in Extroversion, Openness to Experience, and Conscientiousness, compared with normative samples. Further, they demonstrated that incorporating personality variables into the selection procedure would result in significant savings to the agency's training resources by reducing the failure rate of trainees through better initial selection. 
These studies demonstrated that personality variables can be related to performance outcomes. However, because the real world is full of unexpected events, it is important that the human operator in 2 joint system have the ability to appropriately solve problems and to adapt to changing situations. Thus, desirable dimensions of ATCS performance might also be described by one's cognitive style, or one's preferred approach to problem solving.

\section{Cognitive Style}

Cognitive style describes one's preferred "manner" of problem solving. It is a stable preference linked to one's overall personality and is conceptually different from one's capacity for problem solving ("how much"). However, the relationship between cognitive style and performance in air traffic control tasks has received little attention.

Kirton (1976) developed 2 theory of cognitive style that focused on people and their changing environment. He proposed that one's manner of dealing with problems and uncertainty is distinct from one's capacity to deal with problems (e.g., IQ, level of creativity, level of complexity) and from learned techniques, such as the use of brainstorming or memory aids to ind solutions. That is, how one reacts to novel situations that require unique or creative solutions is largely influenced by one's preferred cognitive style. Potentially, one's style would influence performance outcomes, including an individual's efficiency and effectiveness, interactions between individuals, and the outcomes of those interactions in terms of safety and efficiency.

Kirton's theory defines 2 continuum of behaviors ranging from extreme adaptation to extreme innovation. The framework is value-free. No position can be described as being betrer or worse than another. To

\section{Table 1. General characteristics of Adeptors and innovators}

\begin{tabular}{|c|c|}
\hline $\begin{array}{l}\text { Make it better } \\
\text { Use existing rules, methodical } \\
\text { Very efficient a disciplined } \\
\text { Seek consensus } \\
\text { Prefer defined problems } \\
\text { Work inside constraints } \\
\text { Provide balance for Innovators' wild ideas } \\
\text { Can cling to the paradigm too long }\end{array}$ & $\begin{array}{r}\text { Make it different } \\
\text { Orallengerules } \\
\text { Unconventional } \\
\text { Unconcerned with consensus } \\
\text { Redefine problems } \\
\text { Disregard traditional ways } \\
\text { Provide balance for Adaptors' reliance on structure } \\
\text { Can abendon the peradigm too soon }\end{array}$ \\
\hline
\end{tabular}

identify one's cognitive style, Kirton developed the Kirton Adaptation-Innovation Inventory (KAI), a 32-item inventory that produces an overall score for the individual completing the inventory. The range of possible scores yields a continuum on which no location is praiseworthy or censurable. Each score is associated with a range of characteristics that can be perceived as advantageous or disadvantageous depending upon the rater, the nature of the problem, and the nature of the setting, group, or outcome. A strength in one situation could be a weakness in another. While both Adaptors and Innovators are capable of generating original, creative solutions, they will usually do so in their own different, characteristic ways.

An important point to note is that Adaptors and Innovators can be described either by their KAI score's position relative to the range of possible scores or by their score's position relative to the score of another person. That is, relative to the range of possible seores, a person scoring at the high end of the scale would be classified as an Innovator and a person scoring roward the low end of the scale would be labeled an Adaptor. However, relative to another person's score, someone scoring towards the low end of the scale can still be a relative Innovator, compared with someone whose seore was even lower on the scale. For the present purpose, Adaptors and Innovators were conceptualized in an absolute sense and categorized by their relationship to the range of possible scale values. This method, although creating an arbitrary dichotomy, allows greater contrasts to be made. Table 1 contrasts the characteristics of the two cognitive styles.

Kirton (1994) noted that those toward the_Adaptors end of the continuum are more "at home" within systems, valuing precision, reliability, and efficiency. Thus, the person best suited to work within established structures reduces conflict, minimizes risks, and "solves problems by proceeding at a disciplined pace in a predictable direction" by using 2 set of reliable strategies to handle recurring problems (pg. 13). However, a weakness of Adaptors is that they can fail to recognize when their reliable strategies are not appropriate for 2 new problem. 


\section{Cogritive Capacity}

Cognitive style has often been confused with other measures of cognitive capacity, such as intelligence (Kirton, 1994). An individual's capacity for thinking has long been of interest to researchers in many fields (i.e., intelligence, creativity, cognitive complexity). A variety of testing instruments has been developed that attempt to measure "how well" or "how much" 2 person can think.

Intelligence is generally defined as the ability to profit from experience, and tests to measure types of intellectual capacity abound. A general characteristic of these tests is that they categorize an individual according to wherher he or she performed better or worse relative to others taking the test and use predetermined criteria. This is in contrast to Kirton's conceptualization of cognitive style, which does not distinguish between which style is better or worse than another.

Despite the long history of intelligence measurement, however, the relationship between intelligence and performance has not been completely specified (Perkins, Farady, \& Bushey, 1991; Wagner \& Oliver, 1996), particularly for tasks such as air traffic control which require situation modeling and updating, although a minimum level of intelligence would be expected to be necessary to manage complex cognitive tasks (M. J. Kirton, personal communication, July $21,1998)$. In addition, other variables have also been associated with performance outcomes, such as reasoning ability (Voss, Perkins, \& Segal, 1991), familiarity with the problem (Alba \& Hutchinson, 1984; Klein, 1993), and task load (Salas, Driskell, \& Hughes, 1996).

Therefore, the purpose of this study was to examine whether a person's cognitive style would influence performance outcomes in tasks resembling air traffic situations as compared with cognitive capacity, problem familiarity, or task difficulty. A laboratory-based study was conducted to identify whether cognitive style was a concept likely to be fruitful for subsequent research with incumbent air traffic personnel and trainees and to reduce the initial organizational costs associated with personnel selection and training.

\section{RESEARCH QUESTION}

This project tracked performance across several learning stages to determine whether cognitive style would influence performance outcomes in a complex dynamic task. Air traffic control is a system of stipulated control procedures and organization, with system goals of safety and efficiency. In this environment, human judgment can have a significant effect on system goals. Kirton's Adaptor-Innovator theory predicts that Adaptors would perform better than Innovators within a structured, highly proceduralized environment. Specifically, participants who score toward the Adaptive end of the seale will perform better (e.g., make fewer procedural errors) during a dynamic air traffic scenario, relative to those participants who score toward the Innovator end of the scale throughout screening, practice, and task performance.

\section{METHOD}

\section{Participants}

Two hundred high school graduates were recruited through 2 loeal temporary help provider and were compensated for their participation. The provider screened for age, normal color vision, computer skills (ability to use a mouse), high school degree, and aviation experience. Participants were selected so that males and females were equally represented.

\section{Materials}

Three pencil-and-paper self-report measures were used: the KAI instrument as a measure of cognitive style, the Shipley Institute of Living scale as a measure of cognitive capacity, and a two-item assessment of familiarity with computer games.

Measure of Cognitive Style. The 32-item Kirton Adaptation-Innovation Inventory (KAI) was used as the measure to locate respondents on the adaptivenessinnovativeness continuum. The participants indicated how difficult each deseribed behavior was for them to maintain consistently. Participants responded by putting an $\mathrm{X}$ in a blocked area labeled as either: "Very Hard," "Hard," "Easy," or "Very Easy." After adjusting for reversed scoring of some items, high scores reflected preference for innovativeness and low scores a preference for adaptiveness.

Measure of Cognitive Capacity. General intellectual functioning was measured by the Shipley Institute of Living Scale composed of two sub-scales: a 40-item test to assess vocabulary and 220 -item test of abstract thinking (i.e., inference, pattern recognition). This scale has been demonstrated to be uncorrelated with cognitive style as measured by the KAI (Kirton, 1994). 
Assessment of Computer Game Familiarity (CGF). To assess task familiarity, participants' experience with computer games was measured. Young, Broach, and Farmer (1997) found that performance on the Air Traffic Scenario Test, a computer administered low-fidelity radar simulation, was correlated with computer game experience. Specifically, people who had more experience with computer games also were better at routing and handing off aircraft. Based on these results, the general level of participants' familiarity with computer games was measured by a pencil-and-paper test. To assess both attitude and frequency dimensions of familiarity (Alba \& Hutchison, 1984), participants were asked two questions: "How much do you like to play computer games and other similar forms of entervainment?" and "How offen do you play computer games or other similar forms of entertainment?" Participants responded on a Likert scale anchored by 1 (not at all) 806 (very much). A CGF score was computed for each participant by using the average of these two responses.

\section{Scenarios}

The Controller Teamwork Evaluation and Assessment Methodology (CTEAM) research platform was used to present the dynamic air traffic scenario tasks. The device consists of four computer networked workstations. CTEAM was developed to capture important characteristics of a four-sector radar-based air traffic control environment, such as definite rules and procedures (e.g., correct speed for lendings), multiple competing tasks, perceptual and cognitive requirements, and communications (Bailey, Broach, Thompson, \& Enos, in press). Each sector has two airports and four exit gates, of which only two gates connect with other CTEAM sectors.

\section{Performance Metrics}

Participants operated as part of a four-person team and coordinated their activities with adjacent sectors to negotiate the transfer of aireraft from one sector to the next. CTEAM sofiware automatically recorded the number of times separation was lost between two aircraft, number of erashes, number of procedure-following errors (e.g., not bnding at the correct speed), and percent of aircraft reaching their destination. A loss of separation was recorded when two aircraft violated a " 5 horizontal miles" inter-aircraft or aircraft-sector boundary distance rules. The software determined "miles" using screen coordinates. A crash was recorded when two aircraft collided or when one aircraft collided with a sector boundary or an airport. Because separation was lost between two aircraft before they crashed, number of crashes was confounded with loss of separation. Furcher, individual scores on percent of aircraft reaching destinetions were dependent on the other team members' performance, since the aircraft activated in one's own sector had to fly through the three other sectors to reach its destination airport. Because crashes and percent reaching destination were unclear measures of individual performance, the two scores used to represent individual performance were separation violations and procedurefollowing errors. The average of these two measures was used to represent individual performance in that scenario.

\section{PROCEDURE}

\section{Screen}

Thescreening procedure acquainted participants with the basic procedures for successfully performing the task. The screening procedure also eliminated from further participation those candidates who could not grasp a basic understanding of the procedures required to carry out the air traffic control task (e.g., make appropriate changes in aircraft direction, speed, and altitude). Participants were given an orientation to the task and were allowed time for practice to familiarize themselves with use of the equipment, the airspace, and the command procedures. Participants then completed three, tenminute practice scenarios and completed the Shipley Institure for Living Scale. Participants who met specified performance criteria were asked to return for the practice and experimental sessions.

\section{Practice Trials}

One hundred and eighty-four participants who passed the screen returned in groups of four for the practice session. They reviewed the procedures and completed three 10-minute sessions to practice the procedures under three levels of scenario difficulty. Levels of scenario difficulty were calibrated a priori by Bailey et al. (in press).

\section{Experimental Trials}

Each group of four was randomly assigned to one of three experimental conditions based on scenario difficulty (low, medium, high). Each team completed two 28-minute experimental trials. Level of scenario difficulty for each team was determined a priori, remained the same for both trials, and was randomized across teams. 


\section{RESULTS}

Data from 184 participants who passed the screen were analyzed. Observations with missing values were not included in the analyses. The relationship between cognitive style and cognitive capacity was to determine if prior findings of no relationship were replicated in this sample. No relationship was found between $\mathrm{KAI}$ scores and scores on the Shipley Institute of Living Sale ( $r=$ $.035, p<.64, n=181$ ). Moreover, no relationship was found between KAI scores and either of the Shipley's subscale scores. This result supports Kirton's (1976) premise that cognitive style is orthogonal to (i.e., distinct from) cognitive capacity.

Two individual performance seores that were mensured during each session (losses of separation and number of procedure-following errors) were used as dependent measures in analyses of the screening, practice, and experimental trials. Each participant's number of separation losses and procedure-following errors were averaged for each trial to generate an overall individual performance score for that trial. For all analyses, higher numerical scores represented poorer performance. The distribution of the KAI scores was trisected. Scores in the lowest third were nominally labeled the Adaptor group $(n=58)$ and those in the highest third were labeled as the Innovator group ( $n=60$ ). A significance level of $p<.05$ was adopted for all analyses.

\section{Screen}

To determine whether cognitive style influenced performance during the screening, a mixed design, general linear model analysis of variance was performed. Between-subjects variables were Cognitive Style (Adaptor, Innovator), Shipley subscale score (Abstract, Verbal) and CGF score. The within-subject variable was Trials; average individual performance during each screening scenario was the repeated dependent variable. Average performance seores observed during the screening session ranged from 0 to 8 , with means (and standard deviations) over the three screening Trials of 1.91 (1.54), .86 (1.11), and .56 (.93) respectively.

Independent variables Cognitive Style and CGF score did not have significant effects on performance in the screening session, while the Shipley Verbal ( $F_{1}$ $\left.{ }_{101}=10.56, M S e=2.29, p<.0016\right)$ and Abstract $\left(F_{1,101}\right.$ $=6.73, \mathrm{MSe}=2.29, p<.0109)$ subscale scores were significantly related to performance during this task.

Performance over Trials was significant $\left(F_{2,202}=\right.$ $12.88, M S e=1.10, p<.0001$ ), as well as the Verbal $x$ Trials $\left(F_{2,202}=7.10, M S e=1.10, p<.001\right)$ and $C G F$ score $\times$ Trials $\left(F_{2,202}=4.32, M S e=1.10, p<.015\right)$ interactions. The Cognitive Style $x$ Trials and $\mathrm{Ab}$ stract $x$ Trials interactions were not significant. Figure 1 shows the general improvement in performance for both Adaptors and Innovators.

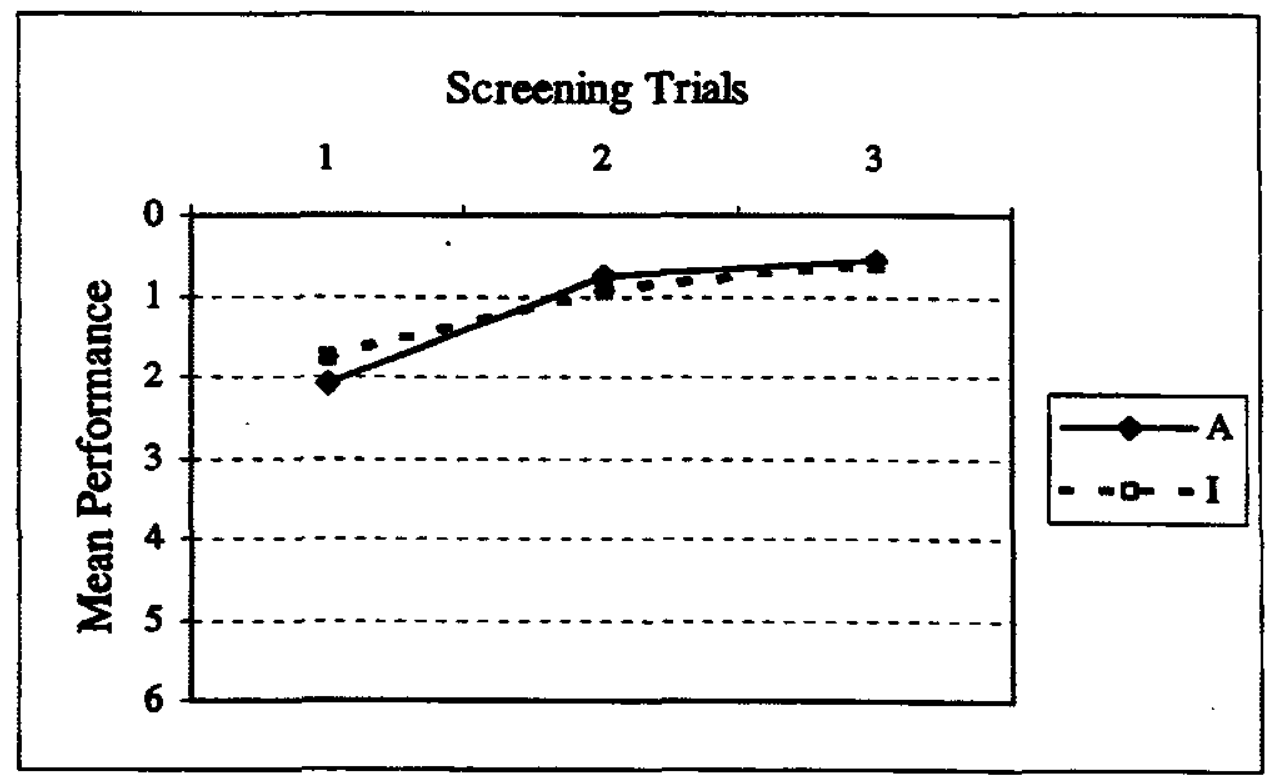

Figure 1. Screen Performance and Cognitive Style. Note that lower scores represent better performance. 


\section{Practice Trials}

The practice sessions served to further familiarize those participants who passed the screen with the rules and procedures of the air traffic control tesk and to accustom them to working in the three levels of scenario difficulty, one of which they would be assigned to during the experimental session. The three trials progressively increased levels of scenario difficulty from low to high.

To determine whether cognitive style influenced performance with practice and scenario difficulty, a mixed design, general linear model analysis of variance was performed. Between-subjects variables were Cognitive Style (Adaptor, Innovator), Shipley subscale scores (Abstract, Verbal) and CGF score. The withinsubject variable was Level of scenario difficulty. Average individual performance during each practice scenario was the repeated dependent measure.

Analysis showed a significant effect for Abstract $\left(F_{1,99}=32.07, M S e=4.39, p<. .0081\right)$ on performance. The analysis revealed no significant effects for Cognitive Style, Verbal, or CGF. Based on inspection of the means, it appeared that Level of scenario difficulty had an effect on performance. However, performance scores showed a wide range of variability. Average performance scores observed during the practice scenarios ranged from 0 to 12, with means (and standard deviations) over the three increasing levels of scenario difficulty of 1.14 (1.25), 1.98 (1.84), and 2.75 (2.22), respectively. The within-subject variable of increasing scenario difficulty showed no statistical effect on individual performance $\left(p<.23, ?^{2}=.004\right)$. No interaction effect appeared between Level of scenario difficulty and Cognitive Style. These results suggest that the practice sessions served the purpose of familiarizing participanis with the increasing levels of scenario difficulty.

\section{Experimental Trials}

A mixed design, general linear model analysis of variance was performed. Between-subjects variables were Cognitive Style (Adaptor, Innovator) and Level of scenario difficulty (low, medium, high). The interaction between Cognitive Style and Level was also tested. The within-subject variable was Trial. Shipley subseale scores (Abstract, Verbal) and CGF score were included as covariates. Average individual performance during each experimental trial scenario was the repeated dependent variable.

Analysis revealed no effects of the variables of Cognitive Style, Abstract, Verbal, CGF, or Level of scenario difficulty on performance. Analysis showed no interaction between Cognitive Style and Level of scenario difficulty.

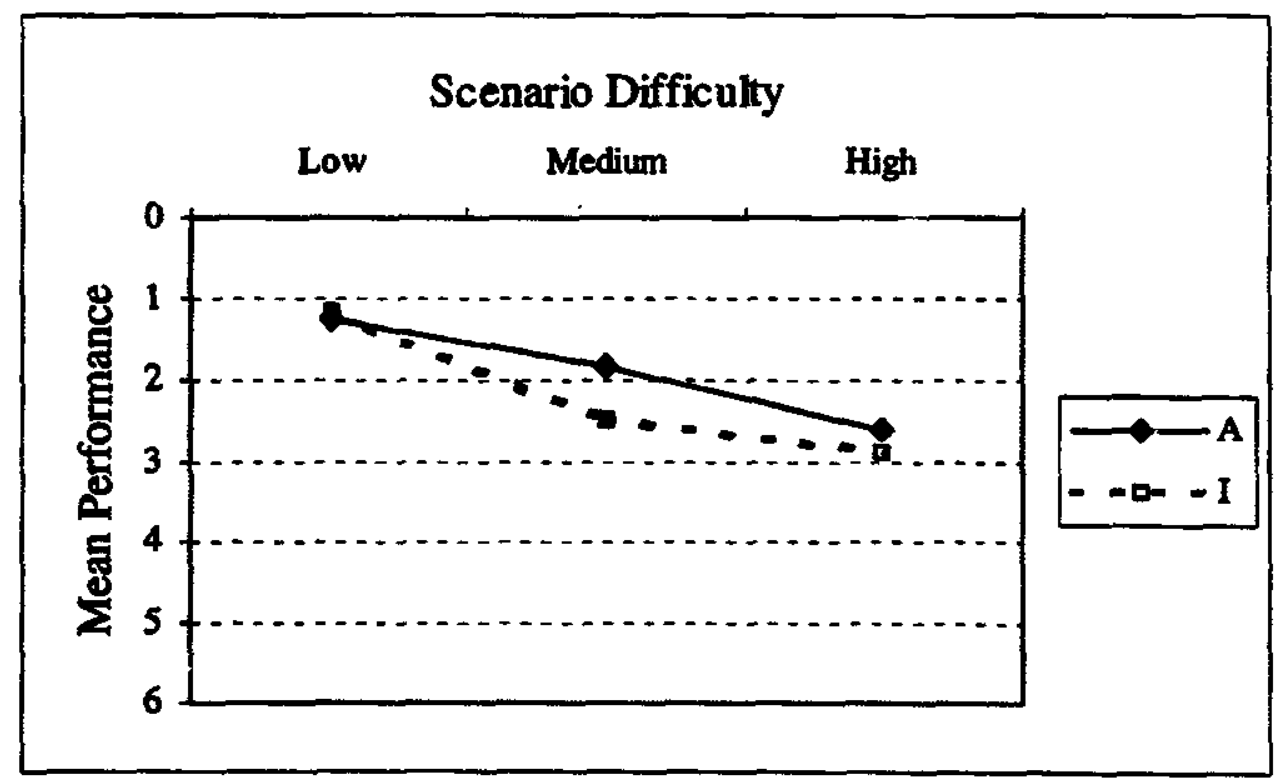

Figure 2. Performance During Practice With Varying Scenario Difficulty. Note that lower scores represent better performance. 


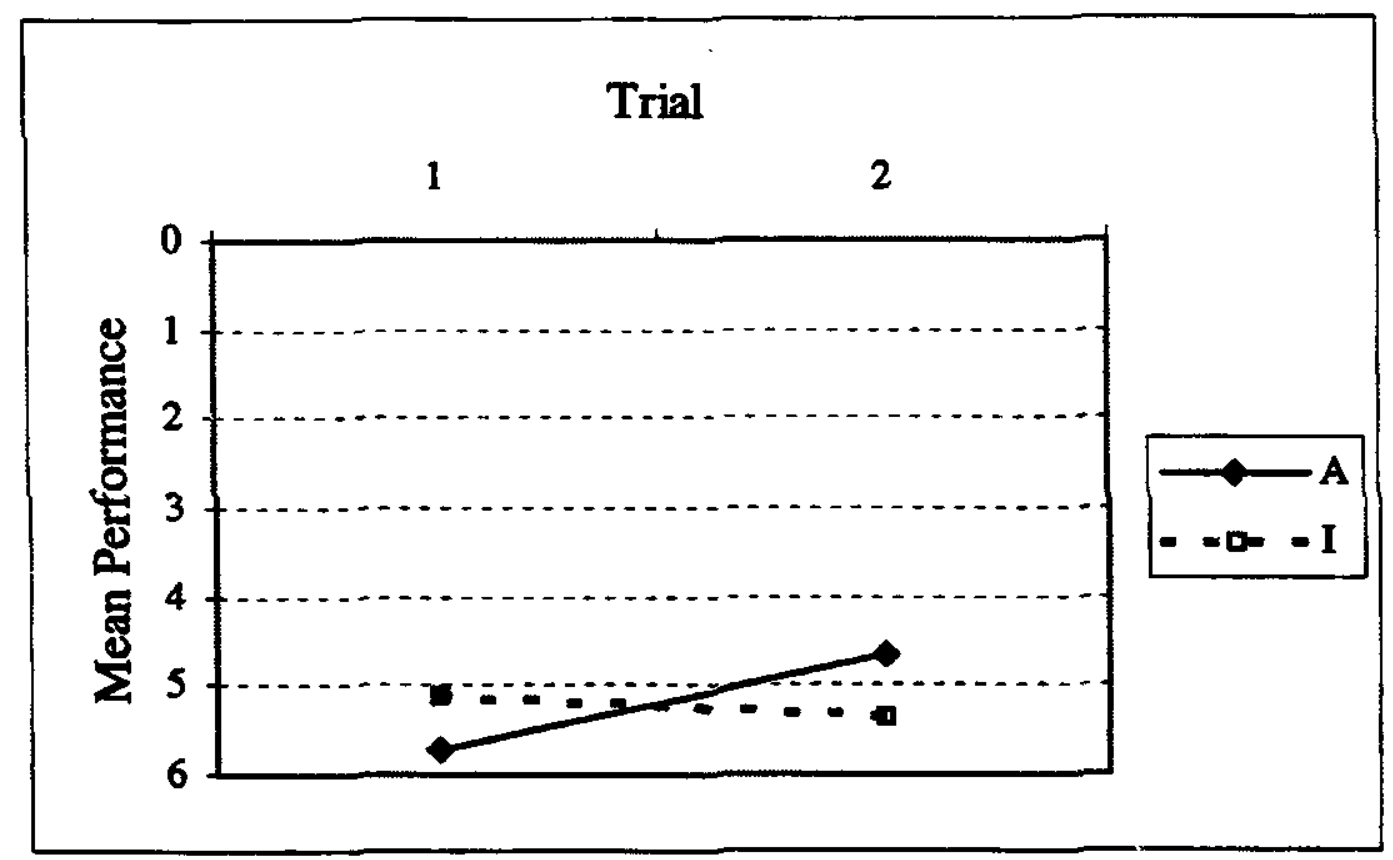

Figure 3. Cognitive Style by Trial Interaction. Note that lower scores represent better performance.

Tests of the within-subject effects revealed a main effect for Trial $\left(F_{1,4} 10.38, M S e=5.68, p<.0018\right)$. Performance generally improved from Trial 1 to Trial 2. Average performance scores observed during the experimental scenarios maged from 0 to 17.5 , with means (and standard deviations) over the two trials of 5.41 (2.93), and 4.98 (3.19) respectively.

Cognitive Style interacted with Trial $\left(F_{1,4}=6.82\right.$, MSe $=5.68, p<.0107)$. Performance of Adaptors improved over trials while Innovators' performance worsened (Figure 3). Trial $x$ Level of scenario difficulty and Trial $\times$ Cognitive Style $x$ Level of scenario difficulty were not significant.

\section{CONCLUSION}

Kirton's (1976) theory of Adaptors and Innovators suggested cognitive style would influence performance and that Adaptors would outperform Innovators on procedure-bound tasks. Thus, the purpose of this study was to examine theoretical predictions about the influence of cognitive style on general performance when learning a complex, dynamic task. Participants' overall performance was followed through screening, practice, and experimental trials.

The hypothesis that cognitive style would influence performance was partially supported. Differences in cognitive style were statistically evident only during the experimental trials. The general pattern of results suggests that Innovators might have had an initial advantage, although Adaptors eventually surpassed them in performance, either because Adaptors generally benefited more from practice or because Innovators were unable to maintain their initial level of performance under continuing conditions.

During screening, while learning rudimentary task skills, high Innovators were expected to have an initial advantage. According to Kirton's theory, novel situations favor Innovators. However, cognitive style did not influence performance outcomes during this exercise. Rather, performance appeared to be zanore strongly influenced by participanes' familiarity with computer games and by their abstract and verbal reasoning skills. This suggests that, although Innovators may have had some initial advantage because of the novely of the task, both Adaptors and Innovators developed strategies for the task as they gained experience with the basic procedures. Thus, although one's cognitive style might influence one's strategies for performance, in this situation, there was little differential impact on performance during initial learning of the fundamentals of the task.

In the practice sessions, abstract reasoning skill, rather than cognitive style, influenced performance. The practice session allowed everyone who passed the screen to rehearse the rules of the scenarios under increasing levels of scenario difficulty. It is possible that Adaptors and Innovators performed differently 
in response to varying levels of difficulty. However, the practice trials did not reveal this, possibly due to the tutorial nature of the task.

In the two 28-minute experimental trials which required participants to repeat and sustain performance for longer periods, performance appeared to be influenced by cognitive style. Adaptors improved their performance in the second trial, while Innovators' performance declined.

Surprisingly, the level of scenario difficulty did not show a statistically significant effect on performance in either practice or experimental trials. At first, these results seemed at odds with results of the scenario calibration study conducted by Bailey et al., (in press). However, examination of the means for the levels of scenario difficulty revealed a pattern of performance similar to the one demonstrated in the Bailey et al. study, (i.e., increasing difficulty resulted in poorer performance). Although differences might be attributed to the variability of performance, an alternative explanation would be the differences in the types of scores used to represent performance in the two studies. The present study used only the two individual performance scores (i.e., separation violations and procedure-following errors) to represent performance, whereas Bailey et al. used a combination of individual and team scores to represent overall performance.

In sum, these results suggest that people who score as high Adaptors might be expected to perform better than high Innovators in this type of procedure-bnund task, al though the Adaptors did not dominate Innovators throughout the entire continuum of learning. Innovators appeared to initially outperform Adaptors in each task. Further research might be able to clarify this observation. Whether Adaptors would continue to outperform Innovators over time deserves further attention.

These analyses examined only individual performance measures. However, research in other domains has demonstrated that teams that were created based on Adaptor-Innovator dimensions resulted in team performance differences (Hammerschmidr, 1996). Therefore, future analyses will use ream performance scores to examine whether cognitive style differences in overall teams also hold for this type of dynamic procedure-bound scenario.

Although the primary emphasis of this study was to examine the influence of cognitive style on performance in a dynamic task under varying levels of difficulty, participants also provided subjective workload ratings. Future analyses will examine the relationship between scenario difficulty and subjective workload ratings for Adaptors and Innovators. To conclude, the question of whether Adaptors would continue to outperform Innovators over time merits additional attention relative to issues of maintaining performance levels, workload, and team performance.

\section{REFERENCES}

Alba, J. W., \& Hutchinson, J. W. (1984). Dimensions of consumer expertise. Journal of Consumer Research, 13, 411-54.

Bailey, L. L. (March, 1998). A look inside group dynamics: The role of group feedback. Presentation at the Oklahoma-Kansas Judgment and Decision Making Conference. Stillwater, Oklahoma.

Bailey, L. L., Broach, D. M., Thompson, R. C., \& Enos, R. J. (in press). Controller teamwork evaluation and assessment methodology (CTEAM): A scenario calibration study. Washington, DC: Federal Aviation Administration Office of Aviation Medicine.

Broach, D., \& Brecht-Clark, J. (1994). Validation of the Federal Aviation Administration air traffic controlspecialist pre-training screen. (DOT/FAA/ AM-94/4). Washington, DC: Federal Aviation Administration Office of Aviation Medicine. Available from: National Technical Information Service, Springfield, VA 22161. Order \#ADA277549.

Chidester, T. R., Kanki, B. G., Foushee, H. C., Dickinson, C. L., \& Bowles, S. V. (1990). Personality factors in flight operations: Volume 1. Leader characteristics and crew performance in a fullmission air transport simulation (NASA Tech. Mem. No. 102259). Moffett Field, CA: NASAAmes Research Center.

Collins, W. E., Schroeder, D. J., \& Nye, L. G. (1989). Relationships of anxiety" scores to academy and field training performance of air traffic control specialists. (DOT/FAN/AM-89/7). Washington, DC: Federal Aviation Administration Office of Aviation Medicine. Available from: National Technical Information Service, Springfield, VA 22161. Order \#ADA209326. 
Furnham, A. (1995). The relationship of personality and intelligence. Perspectives on individual differences. In D. H. Saklofske \& M. Zeidner (Eds.), International handbook of personality and intelligence. Perspectives on individual differences (pp. 397-13). New York: Plenum.

Goodenough, D. R., Oltman, P. K, Snow, D., Cox, P. W., \& Markowitz, D. (1991). Field dependenceindependence and embedded figures performance. In S. Wapner \& J. Demick, (Eds.), Field dependence-independence: Cognitive style across the life span (pp. 131-48). Hillsdale, NJ: Erlbaum.

Hammerschmidt, P. K. (1996). The Kirton Adapontion-Innovation Inventory and group problem solving success rates. Journal of Creative Behavior, 30(1), 61-74.

Hoc, J., Cacciabue, P. C., \& Hollnagel, E. (Eds.). (1995). Expertise and technology. Hillsdale, NJ: Erlbaum.

Hollnagel, E., Cacciabue, P. C., \& Hoc, J. (1995). Work with technology: Some fundamental issues. In J. Hoc, P. C. Cacciabue, \& E. Hollnagel (Eds.), Expertise and technology (pp. 1-15). Hillsdale, NJ: Erlbaum.

Kirton, M. J. (1976). Adaptors and innovators: A description and measure. Journal of Applied Psychology, 61, 622-29.

Kirton, M. J. (1994). Adaptors and innovators. Styles of creativity and problem solving. New York: Routledge.

Klein, G. A. (1993). A recognition-primed decision (RPD) model of repid decision making. In G. A. Klein, J. Orasanu, R. Calderwood, \& C. E. Zsambok (Eds.), Decision making in action: Modelsand methods (pp.138-47). Norwood, NJ: Ablex.

McCrae, R. R., \& Costa, P. T., Jr. (1990). Personality in adulthood. New York: Guildord Press.

Nye, L. G., \& Collins, W: E. (1991). Some personality characteristics of air traffic control specialist trainees: Interactions of personality and aptitude test scores with FAA Academy success and career expectations. (DOT/FAA/AM-91/8). Washington, DC: Federal Aviation Administration Office of Aviation Medicine. Available from: National Technical Information Service, Springfield, VA 22161. Order \#ADA238027.
Perkins, D. N., Farady, M., \& Bushey, B. (1991). Everyday reasoning and the roots of intelligence. In J. F. Voss, D. N. Perkins, \& J. W. Segal (Eds.), Informal reasoning and education (pp. 83-105). Hillsdale, NJ: Erlbaum.

Sales, E., Driskell, J. E., \& Hughes, S. (1996). Introduction: The study of stress and human performance. In J. E. Driskell \& E. Salas (Eds.), Stress and human performance (pp. 1-45). Mahwah, NJ: Erlbaum.

Schroeder, D. J., Broach, D., \& Young, W. C. (1993). Contribution of personality to the prediction of success in initial air traffic control specialist training. (DOT/FAAAM-93/4). Washington, DC: Federal Aviation Administration Office of Aviztion Medicine. Available from: National Technical Information Service, Springfield, VA 22161. Order \#ADA264699.

Spielberger, C. D. (1979). Preliminary manual for the State-Trait Personality Inventory. Tampa, FL: Human Resources Institute, University of South Florida, Human Resources Institute.

Voss, J. F., Perkins, D. N., \& Segal, J. W. (Eds.). (1991). Informal ressoning and education. Hillsdale, $\mathrm{NJ}$ : Erlbaum.

Wagner; R. K., \& Oliver, W. L. (1996). How to get to Carnegie Hall: Implications of exceptional performance for understanding environmental influences on intelligence. In D. K. Detterman (Ed.), Current topics in human intelligence: Vol. 5 . The environment (pp. 247-55). Norwood, NJ: Ablex.

Young, W. C., Broach, D., \& Farmer, W. L. (1997). The effects of video game experience on computer-based air traffic controller specialist, air traffic scenario test scores. (DOT/FAA/AM-97/4).). Washington, DC: Federal Aviation Administration Office of Aviation Medicine. Available from: National Technical Information Service, Springfreld, VA 22161. Order \#ADA322774

Zsambok, C. E., \& Klein, G. (Eds.). (1997). Naturalistic Decision Making. Mahwah, NJ: Erlbaum. 